\title{
Epidemiology, risk factors, type and outcome of stroke in health care facilities of Lomé, Togo: A prospective study
}

\author{
Komi Assogba ${ }^{1}$, Mofou Belo ${ }^{2}$, Ekué A. Folly ${ }^{1}$, Kossivi M. Apetsè ${ }^{1}$, Damelan Kombaté1, \\ Koumavi D. Ekouévi ${ }^{3}$, Koffi A. A. Balogou ${ }^{1}$, Eric K. Grunitzky ${ }^{2}$ \\ ${ }^{1}$ Neurology Unit, Campus University Teaching Hospital, Lomé, Togo \\ ${ }^{2}$ Department of Neurology, Tokoin University Teaching Hospital, Lomé, Togo \\ ${ }^{3}$ University of Lomé, Department of Public Health, Lomé, Togo
}

\author{
Email address: \\ seraphinassogba@yahoo.fr (K. Assogba), motftaobelo@yahoo.fr (M. Belo), ekuefoll@yahoo.fr (E. A. Folly), \\ kapetse@ hotmail.com (K. M. Apetsè), damelan03@yahoo.fr (D. Kombaté), ekuek@yahoo.fr (E. Ekuévi), \\ abalogou@yahoo.fr (K. A. A. Balogou),kgrunitz@yahoo.fr (E. K. Grunitzky)
}

\section{To cite this article:}

Komi Assogba, Mofou Belo, Ekué A. Folly, Kossivi M. Apetsè, Damelan Kombaté, Ekué Ekuévi, Koffi A. A. Balogou, Eric K. Grunitzky. Epidemiology, Risk Factors, Type and Outcome of Stroke in Health Care Facilities of Lomé, Togo: A Prospective Study. Science Journal of Public Health. Vol. 3, No. 1, 2015, pp. 25-30. doi: 10.11648/j.sjph.20150301.15

\begin{abstract}
Background: Stroke is the leading cause of permanent disability acquired in the world. Aim: To study the epidemiological indices, risk factors and outcome of stroke. Subjects and Methods: It was a prospective study to collect epidemiological data, clinical presentation and outcome of stroke patients in 28 public and private health facilities in our largest health region. It had covered the period from January to December 2013. Results: A total of 43,558 inpatients were enrolled. Among them, 986 patients had a stroke which frequency was $2.26 \%$. The incidence rate has been estimated to $79.58 /$ 100,000 inhabitants/year. Male subjects were observed in $50.8 \%$ and $49.2 \%$ of females. The mean age was $59 \pm 13.2$ years. Concerning the stroke subtype, ischemic stroke was found with $54.9 \%$ and $45.1 \%$ of hemorrhagic including $10.8 \%$ of subarachnoid hemorrhage. The traditional main risk factors were hypertension $(87.3 \%)$ and diabetes $(17.5 \%)$. The mean time of admission was $55 \pm 20.75$ hours. The average time before beginning first care was $56 \pm 20.74$ hours. Only $44 \%$ of patients had received first aids within 24 hours. The average length of stay was $17 \pm 8.5$ days. The mean modified Rankin scale score at the exit time was $2.3 \pm 0.8$. At discharge, $58.9 \%$ of patient had partial motor deficits and $27.5 \%$ of them died. Conclusion: A good knowledge of risk factors and early signs of stroke by the population will reduce stroke mortality and its functional sequel. All these lacks of assessment increase the delay in the management of patient and lead to permanent deficits.
\end{abstract}

Keywords: Care Facilities, Epidemiology, Municipality, Risk Factors, Stroke

\section{Introduction}

Stroke is the first leading cause of long-term disability and the third cause of death wide world [1-4]. Strokes had represented by $30-50 \%$ of admissions in neurological services in major urban centers of south Saharan African countries [5-7]. The frequency of hypertension is estimated to $10-15 \%$ in the general population and can reach 30-32 \% in urban and semi urban areas $[8,9]$. The combined effects of rapid urbanization, poverty, and ignorance contribute to increase of the epidemiological indicators of cardiovascular and cerebrovascular diseases [10-12]. A good knowledge of these indicators should help to implement relevant strategies and policies, and reduce stroke incidence, mortality and sequels.
The aim of this study was to determine the epidemiological indicators and the risk factor of stroke in the public and private health facilities in the largest health municipality of our country.

\section{Subjects and Methods}

\subsection{Setting}

The study was conducted in the largest heath region of the country. The design was presented to each of the heads of public and private health facilities concerned for their membership. Twenty eight (28) health facilities (8 public and 20 privates) were selected by random to participate in the study based on their carrying capacity. 
The health region covers an area of 90 square kilometers and located along the Atlantic Ocean which is on its southern side. The population was estimated in 2013 to $1,239,000$ inhabitants. It includes all ethnic groups and different cultural practices of the country. The region is divided into five health districts by the ministry of public health.

With regard to public health coverage, it has 14 peripheral health care units, 4 health centers, one district hospital, one regional hospital, and 2 university hospitals.

The private sector has a continuous and progressive growth since 1990. It plays an active part in providing health care. These private facilities are concentrated in areas where public care services are unavailable. All social categories of patients receive care in these privates sector. This private sector accounts 582 care centers with approximately 46,800 patients per year. This sector is also very diverse. In fact, large centers with specialists and modern technical platform coexist with small centers that remain individual health companies. Besides the approved private facilities by the government, there is an informal private sector ranging from small medical offices to allied units that drain approximately 4,000 patients per year.

The traditional sector is poorly known. The number of drained patients remains unknown. The districts of the city have diverse types of accommodation and sanitary condition as the majority of big cities in developing African countries.

\subsection{Assessment}

It was a prospective and longitudinal study to collect epidemiological data, clinical features, and outcome of stroke among inpatients in public and private health facilities in the largest health region of the country. The study has covered the period from January to December 2013.

The study was conducted by the entire staff of the Neurology Department of Campus University Teaching Hospital of Lomé, Togo. A graduated neurology coordinator, and 30 internships with special training in stroke diagnostic, registered daily all new cases of stroke admitted to the 28 selected sites.

Two stroke neurologists discussed the controversial medical history of all retained patients with a diagnosis of stroke. CT scan or MRI (hyper density/signal or hypo density/signal of the brain parenchyma), was read by a senior neuroradiologist.

Patients with first-ever stroke and patients with recurrent stroke as long as the current admission was due to a relapse stroke were included. Patients with loss of consciousness without focal signs, partial seizures with post seizure deficit, a transient ischemic attack, patients who died within 24 hours of admission with no neuroimaging signs, patients with other diagnostic than stroke, and patients not residing in the Municipality were excluded from the study.

The diagnosis of stroke was based on clinical and radiological criteria, established by World health organization [13]. Baseline information was collected and concerned demographic and clinical features, stroke risk factors, stroke subtypes (ischemic or hemorrhagic stroke and subarachnoid hemorrhage), clinical presentation, modified Rankin Scale scores (at entrance and discharge), length of stay period, use of medications, frequency of in-hospital rehabilitation (physical therapy and speech therapy), laboratory (cholesterol, glucose and homocystein serum levels), and the outcome.

Diabetes mellitus was defined as glucose serum levels $>1.26 \mathrm{~g} / \mathrm{l}$. Hypercholesterolemia was defined as cholesterol serum levels $>5.2 \mathrm{mmol} / \mathrm{l} \quad(220 \mathrm{mg} / \mathrm{dl})$. Hyperhomocysteinemia was defined as homocystein serum levels >15 mmol/l. Hypertension was noted as blood pressure $>140 / 90 \mathrm{~mm} \mathrm{Hg}$ recorded at least twice before stroke.

Occupation was either "manual" (including construction, farming, transportation and driving, and unemployed) or "non manual" (management, professional and related, sales/commercial and armed forces).

\subsection{Statistical Analysis}

The model of questionnaire design and data entry was performed using the software Epidata. The software was used to obtain the clearance data and calculate the standard deviation, mean, discrete and continuous distributions of variables, and the $P$ value $<0.05$ were considered statistically significant. The Khi-square test has permit to compare the frequencies and correlation indices observed between multiples variables. The Khi-square formula is found below:

$$
\mathrm{X}_{(\mathrm{l}-1)(\mathrm{c}-1)}^{2}=\sum \frac{(n i-n i)^{2}}{n i^{5}}
$$

$$
\begin{aligned}
& \sum=\text { somme } \\
& \mathrm{n}=\text { total effectif } \\
& \text { ni }=\text { observed effectif in case } \\
& \text { ni' }=\text { theorical effectif } \\
& \text { ni' }=\text { total line } \mathrm{x} \text { total column /general total } \\
& \left(\mathrm{X}^{2}(\mathrm{l}-1)(\mathrm{c}-1)\right)=\text { le Khi deux } \\
& \mathrm{l}=\text { line number } \\
& \mathrm{c}=\text { column number }
\end{aligned}
$$

The coefficient of contingence $\mathrm{C}$ contributes to evaluate the degree of correlation between two variables.

$$
\mathrm{C}=\sqrt{\frac{x^{2}}{x^{2}+n}}
$$

All the patients or their relatives have given informed consent to the study. The study was approved by the Ethics Committee of the Ministry of Public Health.

\section{Results}

\subsection{Epidemiology Findings}

A total of 43,558 patients were recorded in 28 health facilities. Patients without neuroimaging and those excluded from the study encountered for 166 cases $(0.38 \%)$. The stroke patients were noted for 986 . Stroke frequency rate was $2.3 \%$ 
(986/43,558). In public services, 89.2\% (879) patients were recorded and $10.8 \%$ (107) in private health facilities. Health facilities in districts 2 and 5 hosted $96.4 \%$ of patients with strokes (Table I). The incidence rate of stroke was 79.6 per 100,000 inhabitants per year. Male subjects were observed for $50.9 \%$ (502) and $49.1 \%$ (484) for females. The mean age was $59 \pm 13.2$ years and $80.8 \%$ were over 45 years.

\subsection{Clinical Features}

The average hospital admission time was $55 \pm 20.75$ hours Over than one half of patients $(57.7 \%)$ were admitted within the first 24 hours, $37.4 \%$ within 6 hours (extremes: 4-73). The mean time of beginning first care was $56 \pm 20.74$ hours. Only $44 \%$ of patients had received first aids within 24 hours after the onset of clinical manifestations.

The average delay between admission and making brain imaging has been 43 hours (SD: $53 \pm 24$ ). Eighty percent of patients achieved their brain imaging within 72 hours.

Regarding the stroke subtypes, ischemic stroke was noted in $54.9 \%(541 / 986)$ of and $45.1 \%$ (445/986) for hemorrhagic including $10.8 \%$ of subarachnoid hemorrhage. There is a great correlation between the type of stroke and age $(\mathrm{P}<0.05$, 95\% CI). The ischemic stroke was the prerogative of adults and elderly and the hemorrhagic for the most part was encountered in adults (Table II).

\subsection{Risk Factors and Modified Ranking Scale}

Regarding the risk factors, hypertension comes first with $87.3 \%$, followed by diabetes in $17.5 \%$ (Table III). The mean modified Rankin scale score was $3.7 \pm 1.1$ at entrance and $2.3 \pm 0.8$ at discharge. Patients with hemorrhagic stroke, $88 \%$, had needed the assistance of a third person on admission against $61.3 \%$ with ischemic stroke.

The average hospital length of stay was $17 \pm 8.5$ (14.024.3) days. Table IV had shown the distribution of patients according to admission time, first aids time, modified Rankin scale and the average of length of stay.

\subsection{Stroke Outcome}

Stroke mortality accounted for $0.62 \%(271 / 43,558)$ of deaths of all combined causes. The crude mortality rate (among patient with stroke) was $27.48 \%$ (271/986) at all health facilities, with $34.3 \%$ of deaths in the first 72 hours. Young subjects represented $35.9 \%$ and adults, $26.6 \%$ of deaths. Public care units have registered $95.5 \%$ of deaths and $4.5 \%$ in private clinics. The mortality rate has a great correlation with the modified Rankin scale score at admission and the subtype of stroke ( $\mathrm{p}<0.05,95 \% \mathrm{CI}$ ). The hemorrhagic stroke patients with a modified Rankin scale score higher on admission had the highest mortality rate.

Table I. Distribution of the patients according to the sanitary districts

\begin{tabular}{|c|c|c|c|c|c|c|}
\hline & \multicolumn{2}{|l|}{ All patients } & \multicolumn{2}{|c|}{ Stroke patients } & \multicolumn{2}{|c|}{ Municipality's population } \\
\hline & $n^{*}=43,558$ & Percentage (\%) & $n *=986$ & Percentage (\%) & $n^{*}=1,239,000$ & Percentage (\%) \\
\hline District 1 & 958 & 2.2 & 6 & 0.6 & 51,686 & 4.3 \\
\hline District 2 & 4,486 & 10.3 & 77 & 7.8 & 401,678 & 32.4 \\
\hline District 3 & 8,625 & 19.8 & 12 & 1.2 & 327,841 & 26.5 \\
\hline District 4 & 2,439 & 5.6 & 18 & 1.8 & 97,467 & 7.8 \\
\hline District 5 & 27,050 & 62.1 & 873 & 88.5 & 360,328 & 29.1 \\
\hline
\end{tabular}

Legend: $\mathrm{n}^{*}=$ number of the sample; $\%^{\S}=$ percentage

Table II. Distribution of patients with stroke regarding the sub type of strokes, sex and age

\begin{tabular}{|c|c|c|c|c|c|c|c|c|c|c|}
\hline & \multicolumn{4}{|c|}{ IS $\div(n=541)$} & \multicolumn{4}{|c|}{$H S \dagger(n=445)$} & \multirow{2}{*}{\multicolumn{2}{|c|}{ Total }} \\
\hline & Males & & Females & & Males & & Females & & & \\
\hline & $n *=268$ & $\%^{\S}=49.5$ & $n=273$ & $\%=50.5$ & $n=255$ & $\%=57.3$ & $n=190$ & $\%=42.7$ & $n=986$ & $\%=100$ \\
\hline \multicolumn{11}{|l|}{ Age (years) } \\
\hline Young (15-44) & 41 & 15.3 & 24 & 8.8 & 65 & 25.5 & 36 & 18.9 & 166 & 16.8 \\
\hline Adults (45-64) & 119 & 44.4 & 119 & 43.6 & 166 & 65.1 & 119 & 62.7 & 523 & 53.0 \\
\hline Elderly $(>65)$ & 108 & 40.3 & 130 & 47.6 & 24 & 9.4 & 35 & 18.4 & 297 & 30.1 \\
\hline
\end{tabular}

Legend: IS ${ }^{\ddagger}$ : Ischemic stroke; HS $\dagger$ : Hemorrhagic stroke; $n^{*}$ : number; $\%$ : percentage

Table III. Distribution of patients with stroke according to the risk factors

\begin{tabular}{|c|c|c|c|c|c|c|}
\hline \multirow[b]{3}{*}{ Hypertension } & \multicolumn{6}{|c|}{ Type of strokes } \\
\hline & \multicolumn{2}{|c|}{ IS $*$ (number, percentage $(\%)$ ) } & \multicolumn{2}{|c|}{ HS $\dagger$ (number, percentage $(\%))$} & \multicolumn{2}{|c|}{ Total (number, percentage $(\%)$ ) } \\
\hline & 470 & 86.9 & 391 & 87.9 & 861 & 87.3 \\
\hline Diabetes & 120 & 22.2 & 54 & 12.1 & 173 & 17.5 \\
\hline Hypercholesterolemia & 36 & 6.6 & 6 & 1.3 & 41 & 4.2 \\
\hline Hyperhomocysteinemia & 36 & 6.7 & 6 & 1.3 & 41 & 4.2 \\
\hline Alcohol & 18 & 3.3 & 6 & 1.3 & 24 & 2.4 \\
\hline Obesity & 12 & 2.2 & 12 & 2.7 & 24 & 2.4 \\
\hline HIV infection & 6 & 1.1 & 0 & 0.0 & 6 & 0.6 \\
\hline Smoking & 6 & 1.1 & 6 & 1.3 & 12 & 1.2 \\
\hline Others & 12 & 2.2 & 12 & 2.7 & 24 & 2.4 \\
\hline
\end{tabular}

Legend: $\ddagger$ IS: Ischemic stroke; $\dagger$ HS: Hemorrhagic stroke 
Table IV. Distribution of patients according to admission time, first aids time, modified Rankin scale and the average of length of stay

\begin{tabular}{|c|c|c|c|c|c|c|c|c|c|c|}
\hline \multirow{2}{*}{ Hours } & \multicolumn{2}{|c|}{ Admission time } & \multicolumn{2}{|c|}{ First cares time } & \multicolumn{3}{|c|}{ Modified Rankin scale } & \multicolumn{3}{|c|}{ In-hospital length of stay } \\
\hline & $\mathrm{n}=334$ & Percentage (\%) & $\mathrm{n}=334$ & Percentage $(\%)$ & Score & Entrance & Discharge & Age (years) & ALS* (days) & SD $\dagger$ \\
\hline $0-6$ & 125 & 37.4 & 120 & 35.9 & 1 & $1(0.3)$ & $10(4.1)$ & Young (15-44) & 15.7 & 8.7 \\
\hline $7-12$ & 9 & 2.7 & 10 & 3 & 2 & $46(13.8)$ & $177(73.1)$ & Adults (45-65) & 17.3 & 9.3 \\
\hline $13-24$ & 59 & 17.6 & 17 & 5.1 & 3 & $133(39.8)$ & $40(16.6)$ & Elderly (> 65) & 15.3 & 6.5 \\
\hline $25-48$ & 69 & 20.7 & 51 & 15.3 & 4 & $27(8.1)$ & $1(0.4)$ & & & \\
\hline 49-72 & 25 & 7.5 & 64 & 19.2 & 5 & $127(38)$ & $14(5.8)$ & & & \\
\hline $73 \&+$ & 47 & 14.1 & 72 & 21.5 & & & & & & \\
\hline
\end{tabular}

Legend: *ALS= Average length of stay; $\uparrow \mathrm{SD}=$ standard deviation; $\mathrm{n}=$ total number

\section{Discussion}

\subsection{Study Limits}

The study was conducted among selected care facilities including hospitals, districts and peripheral health care units. This reduced the size of the sample because many patients according to their cultural education did not use basic health facilities. The utilization rate of health facilities was estimated to $53.7 \%$ in the municipality. Another limitation was the inpatients only included, it was impossible to collect patients who could not afford hospital care facilities or were more likely to attend traditional healers $[6,14,15]$. However, the consistency of our results with previous studies in the literature provides some validity to the data.

\subsection{Discussion of the Results}

During the study period, 43,558 patients were admitted to 28 clinics and stroke frequency was $2.26 \%$. The incidence rate was 79.6 per 100,000 inhabitants / year. This may reflect the estimated frequency and incidence of stroke attack in the whole municipality. Our incidence and frequency rates are lower than these reported in the literature. It can be the result of the bias in the recruitment of patients or the smallest size of the whole country population which is estimated to 6 million. According to an overlap of studies, the incidence rate for both sexes ranged from 170 to 360 per 100,000 inhabitants between 55 and 64 years, from 490 to $890 / 100,000$ between 65 and 74 years and 1350 to 1790 per 100,000 over 75 years. It is two to three times lower in women than in men between 55 and 64 years old[16,17].

Regarding the African surveys, the incidence rate of stroke is lower, and ranges between 60 and 74.8/100,000 per year $[18,19]$, similar to our findings. It was reported that the incidence rate for stroke is higher in Europe and USA than in Africa according to different cultural characteristics, diet and lifestyle [17].

The difference between the sexes was not statistically significant, but many previous studies have reported a male predominance $[6,7]$.

The mean age of onset was $59 \pm 13.2$. The age group of 45-65 years was the most affected with $51.8 \%$. The average age reported in some studies range from 52 to 55 years old [16,18].

Regarding the age, young aged from 15-44 years accounted for $16.5 \%$, adults aged of $45-64$ for $75.8 \%$, and aged over 64 years, $7.8 \%$. Incidence rates were estimated for these groups respectively to 41.5, 516.6 and 615.3 per 100,000 inhabitants. Stroke is more common in adults and elderly patients than young subjects $[6,7,11,19]$.

Concerning the admission, it was often motivated by the brutal motor deficit syndrome with or without loss of consciousness, as reported by many authors [6-8]. In this study, $37.4 \%$ of patients were received in a health facility before the sixth hour, and $57.8 \%$ before the $24^{\text {th }}$ hour. In the Belgium study, it was observed $55 \%$ of admission before the $6^{\text {th }}$ hour and $98 \%$ during the first 24 hours [20]. The average time of admission was $55 \pm 20.75$ hours.

Our services are far from being in the concept of time is brain regarding the early admission and management of patients. Early initiation of first aid improves survival and functional prognosis of stroke [21]. It is so important to eliminate any factors that delay hospital admission and the providing of first cares. It is necessary, on other hand, to educate the population on the stroke's first symptoms and aware them to avoid transit to traditional healers or basic clinics which are not suitable for this category of patients before being transferred to neurology unit. The admission can also be late by limited resources of patient, as he/her must pay the care charges in setting where there is no global health insurance.

Depending on the subtype of stroke, ischemic attack was observed in $54.9 \%$ and $45.1 \%$ of hemorrhagic. Other previous studies have reported different rates, range from $63 \%$ to $85 \%$ for ischemic attack and $15 \%$ to $37 \%$ for hemorrhagic stroke $[6,22,23]$. This difference is related to the study region, cultural practice, people lifestyle and possible genetic factors that remain to be identified. African stroke subtypes frequencies are different from Europe and USA [21,24-26].

Regarding the stroke traditional risk factors, hypertension was found in $88 \%$ of patients with hemorrhagic strokes and $86.8 \%$ with ischemic attack. Age, race and sex are all strong none modifiable risk factors [12,18,27]. Previous strokes, hypertension, diabetes, heart diseases, smoking and alcohol are the major modifiable risk factors. It has been estimated that stroke incidence could be reduced in half only when hypertension has received an appropriate treatment $[11,16,18]$. One in four adults has hypertension over 40 years and at least $30 \%$ are unaware to have treatment for it. Controlling hypertension is the single and most effective way 
of reducing stroke mortality in the population $[6,7,10,12]$. To achieve this goal, patients were required to undergo the after stroke education care centers.

The average length of stay was $17 \pm 8.5$ days. If our average length of stay is lower than in other studies[20,21], it is because the duration of hospitalization is relatively short due to the fact that hospitalization costs are higher and must be covered by the patient or its family. Patients need to be released as soon as they have a rather small improvement to reduce the hospital costs. In case of public insurance and social security system, the payment process is too slow and difficult.

Concerning the modified Rankin scale score, $85.9 \%$ of patients at admission had needed the help of another person to accomplish at least one task of their daily life whereas $77.2 \%$ of stroke survivors were independent at discharge period. In South African study, 66\% of stroke survivors needed help in at least one task of daily life at hospital discharge [28]. In the present study, $88 \%$ of patients with hemorrhagic stroke need the assistance of another person to accomplish at least one task of daily life at admission against $61.3 \%$ with ischemic stroke. This means that, at admission patients with hemorrhagic stroke are more dependent than those with ischemic stroke.

At the discharge, $95.9 \%$ of survivors from hemorrhagic stroke no longer needed help or needed a discreet help against $75.5 \%$ of patients with ischemic stroke. High modified Rankin scale score at the entrance would probably be a good prognosis factor. It is clear that the medical care of stroke improves remarkably the quality of life of patients.

Stroke deaths accounted for $0.62 \%$ of deaths from all adjusted-causes among which $50 \%$ were adults over 45 . The crude mortality rate was $27.5 \%$. Stroke deaths rate are ranged from $34.9 \%$ to $61.2 \%$ in several studies $[29,30]$. Hemorrhagic strokes are the deadliest with a rate of $34.6 \%$ against $9.9 \%$ for ischemic, as reported in the literature $[6,16,18,28,29]$. It was found that patient with hemorrhagic stroke who did not die during hospitalization, recovered globally better than patients with ischemic attack $(\mathrm{P}<0.05)$. The stroke-adjusted death rate has declined from approximately $98,5 / 100,000$ in 1990 to $50 / 100,000$ in 2010 , in sub Saharan African countries, and suppose to be lower in the coming years[2,6]. Ischemic strokes had better prognosis than hemorrhagic ones [28-31].

\section{Conclusion \& Recommendation}

\subsection{Conclusion}

The findings of this study showed that stroke frequency and incidence rate was low with male predominance and concern four in five adult over 45 years old. There is a long delay in hospital admission and patient first aids giving. Regarding the stroke subtype, ischemic is more frequent than hemorrhagic with a great correlation to age. Hypertension and diabetes are the traditional leading risk factors. Hemorrhagic stroke patient needed more assistance of a third person on admission than ischemic.

Despite the lack of knowledge assessment and poor equipment available, the stroke crude mortality rate still low in this community. The main challenge remains to reduce the young stroke incidence and its after-effects.

\subsection{Recommendations}

There is a lack of knowledge in the population concerning the risk factors and early signs of stroke. This increases the delay in the admission and management of patient, and lead to permanent stroke after-effects and high mortality rate. Controlling hypertension is the most effective way of reducing stroke disability and mortality in the population. All expenditures and related hospital costs which must be charged by the patient or his family remain the major challenges. Patients were highly required to undergo after stroke education care centers.

\section{Acknowledgement}

Acknowledgement to $\mathrm{WHO}$ and GIZ-PADESS to finance this survey.

\section{References}

[1] Suwanwela NC. Stroke Epidemiology in Thailand. Journal of Stroke 2014; 16(1):1-7.

[2] Reinhardt UE, ChengTM. The world health report 2000Health systems: improving performance. Bulletin of the World Health Organization 2000; 78:1064-84.

[3] Zhao D, Liu J, Wang W, et al. Epidemiological Transition of Stroke in China, Twenty-One-Year Observational Study From the Sino-MONICA-Beijing Project. Stroke 2008; 39:1668-74.

[4] de Carvalho JJ, Alves MB, Viana GÁ, et al. Stroke epidemiology, patterns of management, and outcomes in Fortaleza, Brazil: a hospital-based multicenter prospective study. Stroke. 2011; 42(12):3341-6.

[5] Talabi OA. A 3-year review of neurologic admissions in University College Hospital of Ibadan, Nigeria. West Afr $J$ Med. 2003; 22:150-61.

[6] Balogou A.A.K, Grunitzky E.K, Assogba K, Apetsè $\mathrm{K}$, Kombate D, Amouzouvi D. Stroke among young subjects (15-45 years) in the neurology service of Campus University Teaching hospital of Lomé. AJNS, 2008; 27(2):44-51.

[7] Sonan- Douayoua T, Yapo YP, Assi B, et al. Small size brain infarcts in Ivory Coast: Clinical and tomography retrospective study of 113 cases. AJNS 2004;23:31-5.

[8] Cooper RS, Amoah AG, Mensah GA. High blood pressure: the foundation for epidemic cardiovascular disease in African populations. Ethn Dis. 2003; 13:48-52.

[9] Smith SM, Mensah GA. Population aging and implications for epidemic cardiovascular disease in Sub-Saharan Africa. Ethn Dis. 2003; 13:77-80.

[10] Billinghurst JR. Hypertension and stroke in Africans. Trop Doct.2002; 32 (4):193-8. 
[11] Liu S, Zhao D, Wang W, Liu J, Qin L. The trends of cardiovascular risk factors in urban and rural areas of Beijing during 1984-1999. J Cardiovascular \& Pulmonary Diseases $2006 ; 25: 129-34$.

[12] Cappuccio FP, Micah FB, Emmett L, et al. Prevalence, detection, management and control of hypertension in Ashanti, West Africa. Hypertension, 2004; 43:1017-22.

[13] WHO task force on stroke and other cerebrovascular disorders Recommendations on stroke prevention, diagnostics and therapy. Stroke 1989; 20:1407-32.

[14] Liu M, Wu B, Wang WZ, et al. Stroke in China: epidemiology, prevention, and management strategies. Lancet neurology 2007;6: 456-64

[15] Strong K, Mathers C, Bonita R. Preventing stroke: saving lives around the world. Lancet Neurol. 2007; 6:182-7.

[16] Sacco RL, Bodan-Albala B, Gan R, et al. Stroke incidence among White, Black, and Hispanic residents of an urban community: the Northern Manhattan Stroke Study. Am Jour Epidemiol 1998; 147:259-68.

[17] Pickle LW, Mungiole M, Gillum RF. Geographic variation in stroke mortality in Blacks and Whites in the United States. Stroke 1997; 28:1639-47.

[18] Rosamond WD, Folsom AR, Chambless LE, et al. Stroke incidence and survival among middle-aged adults: nine-year follow-up of the Atherosclerosis Risk in Communities (ARIC) Cohort. Stroke 1999; 30:736-43.

[19] Cabral NL, Goncalves AR, Longo AL, et al. Incidence of stroke subtypes, prognosis and prevalence of risk factors in Joinville, Brazil: a 2 year community based study. J Neurol Neurosurg Psychiatry. 2009; 80:755-61.

[20] Ossemann M, Mormont E, Marin V, Jamart J, Laloux P. Identification of factors that influence the hospital admission delay after ischaemic stroke. Rev Neurol 2001;157: 1525-29.

[21] Barsan WG, Brott TG, Broderick JP, Haley EC, de Marler LJR. Time of hospital presentation in patients with acute stroke. Arch Intern Med 1993; 153:2558-61.
[22] Smadja D, Cabre P, May F, et al. ERMANCIA Study Group. Epidemiology of stroke in Martinique, French West Indies: Part I: methodology, incidence, and 30-days case fatality rate. Stroke 2001; 32(12):2741-7..

[23] Phillips MC, Leyden JM, Chong WK, et al. Ischaemic stroke among young people aged 15 to 50 years in Adelaide, South Australia. Med J Aust. 2011; 195:610-4.

[24] Leopoldino JF, Fukujima MM, Silva GS, do Prado GF. Time of presentation of stroke patients in Sao Paulo Hospital. Arq Neuropsiquiatr.2003; 61:186-89.

[25] de Padua Mansur A, de Fatima Marinho do Souza M, Favarato $\mathrm{D}$, et al. Stroke and ischemic heart disease mortality trends in Brazil from 1979 to 1996. Neuroepidemiology. 2003; 22:179_ 83.

[26] Liu M, Wu B, Wang WZ, et al. Stroke in China: epidemiology, prevention, and management strategies. Lancet Neurol. 2007; 6:456-64.

[27] Burchfiel CM, Curb JD, Rodrigez BL, Abbott RD, Chui D, Yano K. Glucose intolerance and 22-year stroke incidence: The Honolulu heart Program. Stroke 1994; 25:951-7.

[28] Connor MD, Thorogood M, Casserly B, Dobson C, Warlow CP, SASPI Project Team. Prevalence of stroke survivors in rural South Africa: results from the Southern Africa Stroke Prevention Initiative (SASPI) Agincourt field site. Stroke 2004; 35:627-32.

[29] Hankey GT, Warlow C. Treatment and secondary prevention of stoke: evidence, costs and effects on individuals and populations. Lancet.1999; 354:1457-63.

[30] Lavados PM, Sacks C, Prina L, et al. Incidence, 30-day casefatality rate and prognosis of stroke in Iquique, Chile: a 2-year community-based prospective study (PISCIS project). Lancet. $2005 ; 365: 2206-15$.

[31] Lavados PM, Hennis AJ, Fernandes JG, et al. Stroke epidemiology, prevention, and management strategies at a regional level: Latin America and the Caribbean. Lancet Neurol. 2007;6:362-72 